\title{
Al and Big Data Standardization: Contributing to United Nations Sustainable Development Goals
}

\author{
Ray Walshe ${ }^{1, *}$, Kevin Casey ${ }^{2}$, Jane Kernan ${ }^{1}$ and Donal Fitzpatrick ${ }^{1}$ \\ ${ }^{1}$ School of Computing, Dublin City University, Dublin, Ireland \\ ${ }^{2}$ Department of Computer Science, Maynooth University, Maynooth, Ireland \\ E-mail:Ray.Walshe@dcu.ie; Kevin.Casey@mu.ie; Jane.Kernan@dcu.ie; \\ Donal.Fitzpatrick@dcu.ie \\ ${ }^{*}$ Corresponding Author
}

Received 19 August 2019; Accepted 04 January 2020;

Publication 23 April 2020

\section{Abstract}

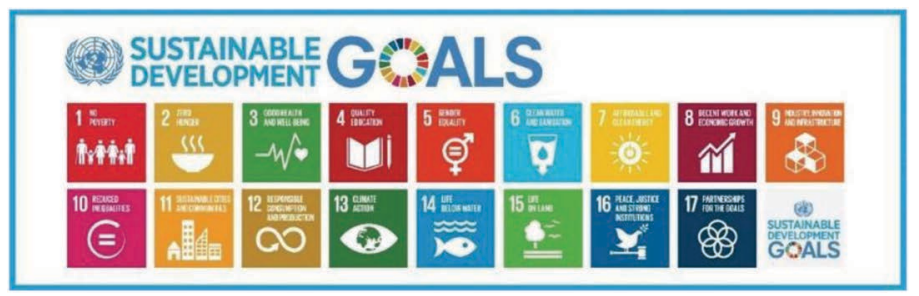

Emerging Technologies like Artificial Intelligence (AI), Big Data, Internet of Things (IoT), Blockchain and 5G communications are innovation accelerators creating new products, processes and industries by disrupting the Information Communication Technologies status quo. International Standards Development Organisations (SDOs) and Standard Setting Organisations (SSOs) develop and evolve consensus documents of the state of the art and publish these international agreements as Standards. In this document the authors present uses cases where some of these emerging technologies

Journal of ICT, Vol. 8_2, 77-106. River Publishers

doi: $10.13052 /$ jicts2245-800X.821

This is an Open Access publication. (C) 2020 the Author(s). All rights reserved. 
can contribute significantly to achieving the United Nations Sustainable Development Goals.

Keywords: Sustainable, development, SDGs, emerging technologies, Big Data, Artificial Intelligence, United Nations, ISO, ITU, IEEE, standards, standardization, SDOs, SSOs.

\section{Introduction}

The United Nations published its 2030 Development Agenda in September 2015, containing 17 Sustainable Development Goals (SDGs), a strategic initiative for achieving sustainability [1]. Standardization bodies, ISO (International Organization for Standardization), IEEE (Institute for Electrical and Electronic Engineers), and ITU (International Telecommunication Union) all have strategy papers on how to achieve the SDGs.

Emerging Technologies like AI and Big Data are not mentioned in the SDGs, the 2030 Agenda for Sustainable Development still claims that the ICTs, in general, can substantially increase progress and bridge the digital divide across communities [2].

In this paper, the authors will explore many ISO, IEEE and ITU ICT standards contributing to the 17 SDGs. New emerging technologies like Big Data and Artificial Intelligence require standardization that is in the early stages but, even so, use cases which employ Big Data and Artificial Intelligences will be used to demonstrate impact on sustainability.

To date, no comprehensive empirical study has been carried out to try to identify and measure the impact of emerging technologies standardization. Such a study requires a critical assessment of the strategies of the international standardization bodies and sound scientific research to extract evidence-based insights impacting on SGDs. Big data and Artificial Intelligence technologies could provide the basis for an investigation of the link between sustainability and standardization.

Big Data and Artificial Intelligence and their wider technological ecosystems are pervasive and cross cutting so many sectors that projects and use cases are identifiable employing the technologies that have a clear and tangible impact on the Sustainable Development Goals. The rapid evolution and development of Big Data and Artificial Intelligence applications requires standardization, regulation and certification to ensure progress is made not just economically but also socially and environmentally. 


\section{Section 1}

\section{(1) The Social SDGs}

2 isis 3 is

The Social Sustainable Development Goals are SDG 2: Zero Hunger, SDG 3: Good Health and Well-Being, SDG 4: Quality Education and SDG 16: Peace, Justice and Strong Institutions. Social sustainability is achieved by standards that help improve the health and well-being of citizens. This includes all aspects of social welfare spanning health, social inclusion and accessibility.

\section{SDG 2: Zero Hunger}

ICT-enabled solutions using Big Data and Artificial Intelligence can help the agricultural sector by increasing crop yields and reducing inputs through making agricultural practices more efficient and data intensive. In 2017, ITU and the Food and Agriculture Organization of the United Nations (FAO) [3] joined forces to bolster ICT innovation in agriculture. With a projected population of 10 billion people by 2050 [4], if the SDGs are to be met, our food production will need to be: inclusive, sustainable, efficient and nutritious. The challenge for the ICT Technologies like Big Data and AI are to ensure inclusion of food systems participants (economic and social, big and small, women and youth), minimize negative environmental impacts and produce abundant nutritious and healthy foods.

Big Data produced by satellite imagery, in combination with AI technology, aids governments and organizations like the World Food Programme (WFP) in understanding the impact of specific shocks on agriculture, in addition to predicting crop yields and future events. The more data that is available, the better the quality of the analysis and the decision making in producing efficiencies. Remote sensing technology empowers the UN Food and Agriculture Organization (FAO) WaPOR project [5] to predict the amount of food that can be produced per unit of water. Policy-makers can use this knowledge to push for better agricultural practices and prioritize areas that can provide optimal usage [6].

"AI can, for instance, enable smallholder farmers in Africa to more effectively address scourges such as viruses and the fall armyworm that 
have plagued the region over the last 40 years despite extensive investment" said David Hughes, Assistant Professor at Penn State University at AI for Agriculture session at 2019 AI for Good Global Summit [7].

In 2017, a UK farm harvested its crop using robots [8]. The planting, fertilizing and harvesting was all carried out by autonomous vehicles.

'Innovations will transform a sector too often characterized in too many parts of the world by poverty and waste.'

- Juergen Voegele, Senior Director,

Food and Agriculture Global Practice, World Bank

In January 2018, a World Economic Forum report identified emerging technology areas that have the potential to do good across many dimensions of the agricultural and food production system [9]. Among the areas identified were IoT for Real-Time Supply, Precision Agriculture, Food Sensing Technologies and Big Data and AI for Insurance. These areas are explicitly or implicitly reliant on Big Data and AI technologies and these technologies generate reductions in food loss of 35 million tonnes, reduction in farmers costs by $\$ 100$ billion, reduction in food waste by 20 million tonnes and generating $\$ 70$ billion of income for farmers. The 1600 ISO food related standards are creating confidence for the food production sector, improving methods, and promoting sustainable and ethical purchasing in agricultural sector.

\section{SDG 3: Good Health and Well Being}

Technology used in the health sector must comply with international standards to ensure safety, security and interoperability [10]. Modern communications technologies ensure more people across the world are connected and able to benefit from the widening range of digital health services offered via wireless communication.

Direct patient interaction, health informatics and telemedicine can be improved through better connectivity. In 2017, ITU and the World Health Organization (WHO) launched the "Digital Health for Africa" [11] partnership to scale up the use of digital technologies to strengthen the delivery of public health care services in Africa. Another ITU and WHO collaboration "Be He@lthy, Be Mobile" [12], enables governments with the introduction of health services for non-communicable diseases (NCDs) using mobile phones to deliver information to citizens. Standards for multimedia systems 
to support the widespread deployment of e-health applications are also under development by ITU, in particular in the area of telemedicine.

High quality healthcare is a fundamental human right. There are more than 1300 ISO standards for medical practices and medical equipment quality. For example, ISO 11137 series covers the healthcare product sterilization by radiation standards and ISO 7153 standardizes materials for surgical instruments. ISO also develops standards to help local governments promote health and well-being in their communities, such as International Workshop Agreement IWA 18, Framework for integrated community-based life-long health and care services in aged societies, and ISO 37101 for the sustainable development of communities.

At the AI for Good Global Summit 2019, futurist Ray Kurzweil during his keynote presentation was very positive about the future of AI, and technology advancements in areas like nanobots, which will lead to "new therapies and diagnoses extending life"

Big Data has become an accelerator for innovation across all industry sectors. ITU and WHO are progressing standardization of a framework to measure 'AI for Health' programs to address health issues such as breast cancer, Alzheimer's disease, vision loss and skin lesions. These evaluation methods will assess if 'Proof of Concept' has been achieved. If accuracy thresholds are achieved, then the process may be used in clinical settings [13].

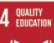

\section{Uİ SDG 4: Quality Education}

Universities are key in shaping digital transformation and progressing skills development in Artificial intelligence and Big data analytics. The theme at the 2nd ITU-Academia Partnership Meeting in Atlanta, Georgia, USA was the need for digital skills and preparing for future skills and future jobs [14]. ITU and the International Labour Organization (ILO) are leading the Digital Skills for Decent Jobs Campaign [15], to equip five million young men and women with job-ready digital skills by 2030 . New approaches to teaching at university level should be adopted and universities need to create the next generation of digital leaders.

Access to the internet is key for quality education and today, over $50 \%$ of the world are online and $90 \%$ are within reach of a mobile broadband network (See Figure 1).

Affordability is certainly a major barrier to greater internet usage. In some countries, a smartphone costs as much as one's monthly income, data 
Mobile population coverage and Internet usage (2018)

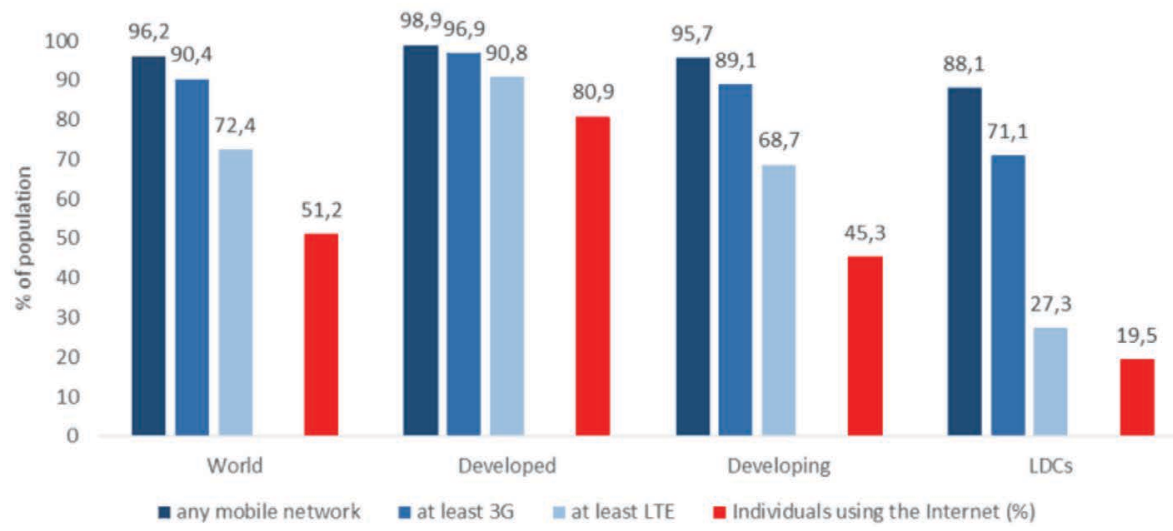

Figure 1 Mobile population coverage and internet coverage - (Source: ITU).

packages are expensive and connection quality is poor. Data shows that over 70 per cent of the world's youth are online. In developed countries, $94 \%$ of young people use the internet but in developing countries the number stands at $67 \%$ [16]. As well as using AI, Big Data and other emerging technologies to provide education, there is also a need for innovative, thoughtful, multi-generational programs about the technologies themselves that foster lifelong learning and knowledge sharing between communities and technology experts from both industry and academia. These programs should help in understanding AI technologies and the impact on us, our brains, and the way we behave [17].

\section{Y SDG 16: Peace, Justice and Strong Institutions}

In October 2017, the ITU published ICT-centric economic growth, innovation and job-creation wherein Government policy affecting ICTs are described that can have a major effect on achieving the SDGs. There are four key areas mentioned:

- Measure and monitor progress where SDGs are outcome-related, e.g. poverty reduction (SDG 1), gender balance (SDG 5), inequality reduction (SDG 10) and economic growth (SDG 8). ICTs and so-called "big data" have a major role to play in this. 
- Use ICTs to enhance government performance to ensure two of the most critical or foundational SDGs are achieved, namely: "peace, and justice for all" (SDG 16), as well "global partnerships" (SDG 17). ICTs to deliver efficient and inclusive services for peace and justice for all.

- Adopt enabling policies for ICT markets (i) ICT infrastructure markets, and (ii) ICT applications and content markets where a significant contribution to two key SDGs: SDG 9 through infrastructure innovation and sustainable industrialization and SDG 12 through sustainable consumption and production patterns

- Adopt enabling policies for non-ICT markets including markets for: food (SDG 2), water (SDG 6), energy (SDG 7), smart-cities (SDG 11), markets for health (SDG 3), education (SDG 4), markets for environmental goods and services like climate (SDG 13), oceans and seas (SDG 14) and terrestrial ecosystems (SDG 15)

Good governance is required at all levels, from start-ups and SMEs through to MNCs and governments. ISO technical committee ISO/TC 309, Governance of Organizations, consolidates best practice for effective governance, from control and accountability, to compliance and whistleblowing. ISO 37001 (anti-bribery management systems) increases transparency and accountability and thus promotes peace, justice and strong institutions.

ITU through its work on smart sustainable cities and measuring social inclusion indicators drives empowerment and engagement. ITU also helps countries deploy broadband connectivity and develop ICT applications to facilitate the provision of free or low-cost digital access for schools, hospitals and underserved populations [18]. Estonians can register a new company, Brazilians can file their taxes, Russians and Argentinians participate in government decisions online and through mobile apps.

AI has come to impact every industry and every discipline. Another area under Peace, Justice and Strong Institutions where there is a lot of untapped potential is the use of AI in assessing large amounts of data regarding disarmament. Big Data and AI can be used in verification, detection, tracing and risk mitigation [19].

"Our challenge is to maximize the benefits of the technological revolution while mitigating and preventing the dangers." - Antonio Guterres, UN Secretary-General AI systems utilised in military automation and control, and weapons raises serious questions, as there are risks in potential accidents, escalation control and accountability [20]. 


\section{Section 2}

\section{(2) The Economic SDGs}

Miniti

The Economic Sustainable Development Goals are SDG 1: No Poverty, SDG 5: Gender Equality, SDG 8: Decent Work and Economic Growth, SDG 9: Industry, Innovation and Infrastructure and SDG 10: Reduced Inequalities. Economic sustainability is achieved by standards that help improve international trade, quality infrastructure and supporting sustainable business practices.

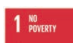

\section{Mivinit SDG 1: No Poverty}

Extreme poverty worldwide is declining at the same time as literacy rates have improved and total expenditures on education is rising [21]. Access to money is still a barrier in developing countries for citizens to escape poverty and "mobile money poverty" is a factor in this. The little money poor people have is hard to manage as it's unpredictable when they will be paid.

'Bank accounts help poor people more effectively confront the problems that keep them stuck in poverty.'

- Leora Klapper, Lead Economist, Development Research Group, World Bank

Infrequent payments need to be stretched a long time between harvests and planting season, while covering daily living costs. If money runs out, they have no food, which makes them less healthy and even more poor. AI and Big Data platforms can be used to underpin Distributed Ledger Technology (DLT) creating a faster payment system and reducing the cost of transactions. By giving the individuals more control, reducing the need for intermediaries and providing 'smart' legal contracts that execute without user intervention provides citizens with financial inclusion and control [22].

\section{$\stackrel{\Theta^{\pi}}{*}$ SDG 5: Gender Equality}

ICT is critical for the social and economic development of women and young females. Emerging technologies can be used to provide education as well as employment. 
According to the 2018 World Economic Forum's Global Gender Gap Report [23], of AI professionals globally only $22 \%$ are female while $78 \%$ are male. Urgent action is needed by all stakeholders to mitigate the threat posed by gender bias outcomes in future AI applications. Emerging technologies, such as Big Data and AI, level the playing field rather than being used to create further digital divide. Big Data can help reduce gender bias in AI systems but only if the human digital gender gap in professionals is addressed.

\section{"Transparency and accountability for the data behind AI is critical to reducing bias, but very difficult to govern or enforce" [24].}

Policy and regulation of emerging technologies such as AI and Big Data, should be a priority for all governments irrespective of the status of national AI development, policy and strategy in their countries. Governance of emerging technologies is a national agenda item for all nations.

Training girls to become programmers like in the African Girls Can Code Initiative (AGCCI) [25] can challenge existing gender stereotypes and narratives; create innovative and inspiring work environments and drive further education and careers in technology. 133 million new jobs will be created by technology by 2022, according to the World Economic Forum (WEF) [26]. That is why it is especially important that we champion getting more girls involved in the technology field so they can access these job opportunities [27].

"Find girls in your family and ask them if they have considered a job in ICT!” [28].

- Dr. Hanane Naciri, Radiocommunication Engineer at ITU

Dr. Naciri (ITU) describes UN International Girls in ICT Day as targeting careers in technology for young women. About 357,000 girls and young women have already taken part in more than 11,100 events at International Girls in ICT Day in 171 countries worldwide.

ISO 26000 [29], Guidance on social responsibility aims to eliminate bias through encouraging a balanced mix of men and women in management and ensure equal treatment in recruitment, career opportunities and parity in pay. 


\section{俔 SDG 8: Decent Work and Economic Growth}

Global population is forecast to reach 8.5 billion people by 2030 at a time when arable land area is decreasing. Climate change effects and declining crop yields are putting greater stress on agriculture and farming. Big data analytics, Artificial Intelligence and other emerging technologies are transforming agriculture to support data-driven agriculture [30].

"For digital agriculture, the key challenge will be in extracting accurate and actionable insights from these innovative technologies and their resulting data streams" [31].

The E-agriculture in action: Big data for agriculture report [32] (ITU and FAO publication), looks at how big data and digital technologies are radically changing the agriculture value chain by extracting actionable insights from these emerging technologies and data. Standardization and interoperability of Big Data and Artificial Intelligence technologies will be indispensable in reaping the benefits of scale.

Interoperability and standardization in the digital ecosystems of big data, $\mathrm{AI}$ and $5 \mathrm{G}$ networks paves the way for more innovative products and services. ITU supports this standardization through the activities of Study Groups 13, 17 and 20 on the standardization of next-generation networks, cybersecurity and Internet of Things (IoT) technologies. ISO/IEC JTC1 supports it through Standards Committees 38, 41 and 42 on standardization of cloud computing, IoT and AI \& Big Data.

In 2018, in Singapore, the Pan Pacific Hotel Group deployed AI and IoT technologies over 30 regional Pan Pacific Hotels Group hotels, resorts, and serviced suites, with Singapore as the lead [33].

International Standards promote economic growth by setting a common vocabulary and internationally consensus on detailed specifications that can be applied in the development of national and international regulation, certification and legislation. Standards are effective and necessary tools for reducing barriers to international trade [34] (interoperability), as acknowledged in the WTO's Agreement on Technical Barriers to Trade.

Also ISO 45001 [35], Occupational health and safety management systems - Requirements with guidance for use, helps protect the health and safety of the people at work. Bribery is another undesirable effect on employment. ISO 37001 [36] on anti-bribery management systems is helping companies fight against the culture of bribery. 


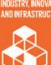

\&

SDG 9: Industry, Innovation and Infrastructure

Smartphones and broadband connectivity allows citizens worldwide to use the internet and other online services [37]. Billions of lives have been improved and progress in achieving each of the United Nations Sustainable Development Goals has been made. The correct policies need to be in place as well as technologies for real and meaningful development to take place.

Realizing the potential of ICTs the government of Myanmar is opening up the market for private sector investment. Following on with further deregulation introducing competition in the telecommunication sector led to increased network coverage, plunging costs to subscribers with access to the fastest 4G services in the region, and the 5G roadmap is being developed. In 2011, SIM card cost hundreds US dollars and the number of mobile subscribers was around 1.24 million in a country with a population of around 54 Million (See Figure 2), In 2018, the number of cellular mobile subscribers reached 61.14 million (which was more than the country's population).

Director General of the World Intellectual Property Organization (WIPO) Francis Gurry is vocal about responsible innovation [38] and the different groups that promote responsible artificial intelligence especially on matters such as lethal autonomous weapons and genome editing.

"We don't want innovation just for innovation's sake. We want innovation that's going to improve the quality of our lives,"

$$
\text { - Francis Gurry (WIPO) }
$$

During the 2019 World Summit on the Information Society Forum [39], a special session organized by the Broadband Commission for Sustainable

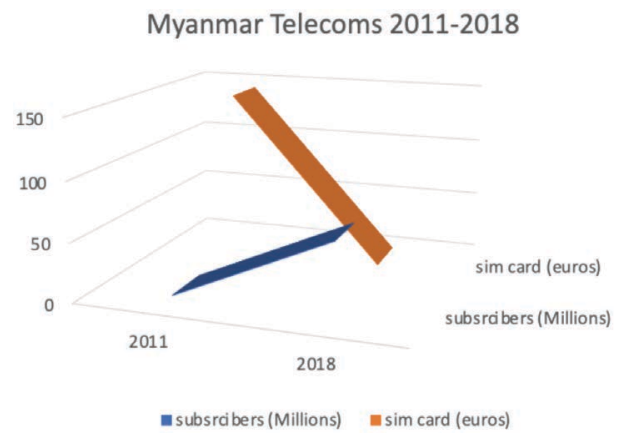

Figure 2 Myanmar telecoms sector 2011-2018. 
Development showed that collaboration with partners is necessary to ensure that the digital transformation is inclusive and caters for all members of society. Progress can be seen in the global trend towards a whole-of-government mindset to digital development which will accelerate progress towards the 17 Sustainable Development Goals, while improving citizens livelihoods and generating economic growth.

Experts from the ICT sector, international organizations and governmental bodies must continue to work together to deliver ICT connectivity, from both the supply and the demand side, eliminating trade barriers, enabling digital services and e-commerce through infrastructure, affordability, digital skills , trustworthiness and security.

International Standards support sustainable industrialization with quality, safety and sustainability requirements so products and services can flourish. Standards provide a universal language, thus breaking down technical barriers to international trade allowing developing countries to compete more easily in the global marketplace. ISO 44001 [40], Collaborative business relationship management systems - Requirements and framework, provides a common platform for collaborative working where companies produce healthy business relationships, both within and without.

ISO/TC 279 Innovation management [41] on systems, tools and methods for collaborative innovation partnership ensures interoperability, provides confidence and encourages investment in innovation.

\section{SDG 10: Reduced Inequalities}

On May 17th 2019 World Telecommunication and Information Society Day focused on inclusive standards under the "Bridging the Standardization Gap" [42]. International standards by definition is a means to share innovation on a global scale and an inclusive standardization processes is the cornerstone economic growth.

Emerging technologies like AI, Big Data, IoT and 5G have the potential to deliver considerable benefits, both social and economic, which help achieve UN SDGs. The ITU standardization platform is supported by their Bridging the Standardization Gap (BSG) [43] programme that assists developing countries to participate in international ICT standards. There are encouraging results from training sessions that assist ITU delegates in developing the practical skills for the standardization process. In just four years, they have been attended by some 500 delegates representing 82 countries. 
ITU deals with intelligent transport in standards for radiocommunications, security, multimedia, and performance and quality of service. Collaboration with United Nations Economic Commission for Europe (UNECE) [44], the body responsible for global vehicle regulation has proved invaluable and is now leading to technical standards to support regulation in intelligent transport systems.

Artificial Intelligence (AI) is impacting on security, algorithms and data analytics. Network 'self-optimization' is crucial to emerging 5G and IoT networks. The World Health Organization (WHO) collaborates with ITU to support Smart Health by evaluating whether 'AI for Health' use cases have achieved "Proof of Concept". The theme of the 2018 UN International Day of Persons with Disabilities [45], "Empowering persons with disabilities and ensuring inclusiveness and equality", mirrors ITU aims that persons with disabilities (PwD) are empowered through ICTs.

When we secure the rights of people with disabilities, we move closer to achieving the central promise of the 2030 Agenda - to leave no one behind.

$$
\text { - António Guterres, UN Secretary-General }
$$

The world's leading SDOs, IEC, ISO and ITU collaborate to benefit the entire standardization ecosystem. Many standards experts participate in all three bodies, and a Joint Task Force focuses on the strategic coordination of global standardization work.

Apart from the above standardization initiatives contributing to the reduction of inequalities, they help to break down barriers to trade, promote innovation and level the playing field for international markets. ISO have a specific standards key to this SDG, ISO 26000:Guidance on social responsibility [46], encompassing the principles of non-discrimination and equal opportunities including human rights, the environment, fair operating practices, consumer issues and community involvement.

\section{Section 3}

\section{(3) The Environmental SDGs}

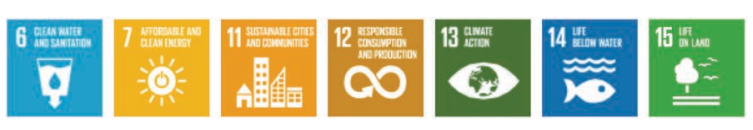

The Economic Sustainable Development Goals are SDG 6: Clean Water and Sanitation, SDG 7: Affordable and Clean Energy, SDG 11: Sustainable Cities 
and Communities, SDG 13: Climate Action SDG 14: Life Below Water and SDG 15: Life on Land. Environmental sustainability is achieved by standards that support environmental management systems, measuring and reducing greenhouse gases and energy consumption.

\section{SDG 6: Clean Water and Sanitation}

"If we want to solve climate change, water governance is our blueprint"

- Will Sarni, Founder and CEO, Water Foundry Callie Stinson, World Economic Forum

Abnormally high temperatures combined with drought have contributed to unprecedented wildfires in many parts of the world. Extreme weather events like severe monsoons in South Asia have hit Bangladesh and tropical storms causing damage in East Africa are examples of risks linked to water.

The World Economic Forum's 2018 Global Risks Report [47], states that risks like financial crisis and chronic diseases emerged and disappeared but water has stubbornly remained.

Stakeholders groups are converging to explore how emerging technologies can help with water and sanitation challenges [48]. The Urban Water Resilience Initiative investigates how Artificial Intelligence, Big Data Analytics, Blockchain and IoT sensors can deliver smart water management (See Figure 3).

The World Bank's Water Global Practice [49] wants to scale groundwater assessment solutions involving Fourth Industrial Revolution technology in emerging economies.

"As the world's largest multilateral source of financing for water in developing countries, the World Bank is working closely with partners to achieve 'A Water-Secure World for All' by sustaining water resources, delivering services and building resilience" [50].

Ericsson is building a smart water network around the Internet of Things. IoT enables real-time water monitoring, the source of the water, its distribution throughout the network, and into the reservoir. This technology, can now continuously monitor water data 24 hours a day.

Agriculture takes $70 \%$ of global water withdrawals, so improving the efficiency of this sector will play a major role in the sustainability of the 


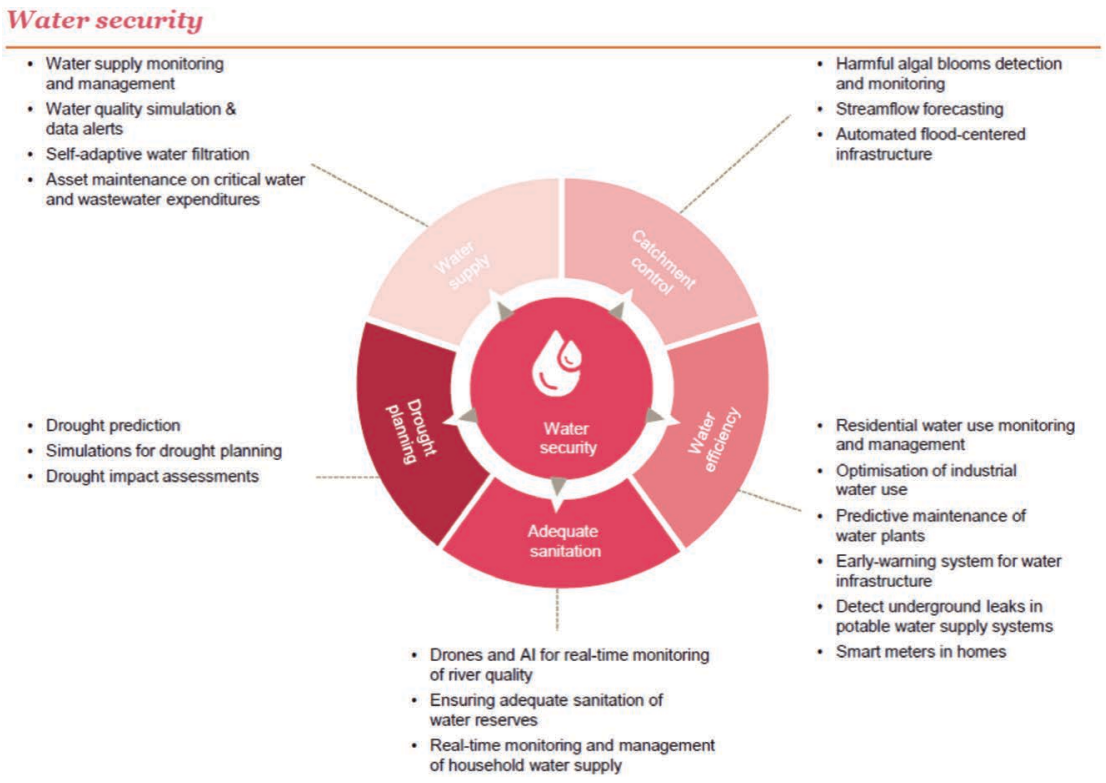

Figure 3 Water security (Source: PwC Research).

world's water resources. AI, IoT sensors and Big Data analytics can provide efficiencies via automation and remote monitoring in not just agriculture but also the monitoring of sewerage networks, so waste is properly disposed of. Emerging technologies in the context of SDG 6 provide water and sanitation equitably to everyone on the planet.

ISO 24521 provides guidance on on-site domestic wastewater systems, making use of alternative technologies using local resources. Standards in this field include the upcoming ISO 30500 [51], Non-sewered sanitation systems - Prefabricated integration treatment units - General safety and performance requirements for design and testing.

\section{SDG 7: Affordable and Clean Energy}

Health and climate change are being affected by unsustainable energy practices making equality in economic development more difficult. Modern sustainable energy policies and systems are the core of achieving SDG 7. UN University focuses on efficient use of natural resources and on boosting sustainable energy sector expertise [52]. 
ICT technologies have contributed towards economic growth, especially in emerging economies, but created challenges in disposing of tech products which have reached end of their life cycle. E-waste incorporating electronic device components and related materials is abandoned or discarded. Accumulation of e-waste in soil and water can cause serious medical issues. $70 \%$ of the hazardous waste reaching landfills worldwide is represented by e-waste [53].

ISO standards provide guidelines and requirements for solutions to energy efficiency and renewable sources. Governments can use them as a basis to create policies to achieve their national and international energy objectives. ISO 50001 focuses on the development and implementation of an energy management system, while the ISO 52000 series help the construction industry attain energy efficiency improvements in energy performance of buildings.

Emerging technologies like AI and Big Data analytics support projects in achieving SDG7 by smart monitoring and control of water system, sanitation systems, renewable energy producing plants and smart manufacturing using circular economy objectives.

\section{SDG 11: Sustainable Cities and Communities}

U4SSC (the United for Smart Sustainable Cities Initiative) consists of 16 UN bodies aiming to "Make cities and human settlements inclusive, safe, resilient and sustainable" and achieve SDG 11.

100 cities have been participating to evaluate sustainability using the U4SSC KPIs which enable planners to assess how ICTs have improved economic, environmental and social aspects of their cities. ITU-T SG20 IoT and smart cities leverages IoT technologies to address urban development challenges. The KPIs are are based on ITU Y.4903/L.1603 "Key Performance Indicators for Smart Sustainable Cities to assess the achievement of Sustainable Development Goals" [54], international standard.

Resource management, preserving the environment and improving the well-being of citizens are addressed by ISO technical committee ISO/TC 268, Sustainable cities and communities, and their standard ISO 37101 helps communities deliver their strategies to achieve their sustainable development objectives.

ISO standards on intelligent transport systems, water management, business continuity and community resilience, are designed to make communities 
safe adaptable and sustainable. Examples are ISO 22313 (business continuity management systems), ISO 22326 (emergency management), ISO 22395 (guidelines for supporting vulnerable people in emergency situations) and ISO 24526 (water efficiency management systems).

Emerging technology-based systems utilising AI, Big Data and IoT to collect vital data, plan city development and management will create more liveable and sustainable cities.

\section{2 asevent}

SDG 12: Responsible Consumption and Production

E-waste is seen as one of the ICT industry's biggest global challenges as mentioned on SDG11, and this creates a challenge in recycling strategies. Electronics supply chains are not known for transparency or sustainability. The T-Mobile, Samsung and Dutch social enterprise Closing the Loop [55], implemented a circular service now commonly known as 'One for One', where a customer buys a new phone, a small fee is added which is used by Closing the Loop to collect the phone when obsolete in a developing country, such as Ghana. The scrap phone is bought in a small shop (creating jobs and income while reducing pollution) and then sent to Europe for recycling where 10 rare and precious metals are extracted.

Addressing e-waste supports the achievement of the Sustainable Development Goals, playing a big contribution to addressing SDG 3, 8, 9, 11, 12 and 13.

Juniper research (technology market research specialist) advises that there is US $\$ 14$ billion savings to consumers to be made if programmes for the development of smart grids are prioritised [56]. Deployment of smart grids will be accelerated not least because of the increasing cost of carbon capture and falling cost of energy such as solar and wind.

Volvo will cease production of cars with internal combustion engines in 2020 , the number of either hybrid or all-electric vehicles is increasing and the demand for power to recharge them will not be met unless action is taken. By reducing the amount of private transport on city streets, traffic congestion and pollution, could be reduced. Individuals in some cities resist parting with their cars but in Beijing and Jakarta immediate action is required.

The use of renewable sources of energy, reduction of environmental impact and responsible purchasing decisions by standards, contributes to sustainable consumption and production. 
ISO 20400, Sustainable procurement-Guidance [57], helps organizations incorporate sustainability into their procurement function. Sustainability is highly relevant to construction technologies, processes and materials. ISO 15392, Sustainability in building construction [58], contains principles for sustainability in buildings and construction throughout the life cycle.

ISO 20245, Cross-border trade of second-hand goods [59], has minimum screening criteria for internationally traded goods and drives this alternative consumption by reducing waste and impact on the environmental.

18 sick

\section{Q SDG 13: Climate Action}

"Let us work together to turn the digital revolution into a climate action revolution." [60]

\section{- Malcolm Johnson, ITU Deputy Secretary-General}

The United Nations agency for ICT is harnessing the potential of emerging technologies such as Artificial Intelligence, Big Data Analytics, the IoT and $5 \mathrm{G}$ to monitor, moderate and adapt to the effects of climate change. Carbon footprints of digital ecosystems are growing, so international standards for sustainability through technology are necessary to create a circular economy [61].

The UN Focus Group on "Environmental Efficiency for Artificial Intelligence and other Emerging Technologies" [62] investigates how to optimize environmental efficiency with AI and other emerging technologies and "United for Smart Sustainable Cities," [63] coordinated by ITU, UNECE and UN-Habitat strives to make cities and settlements inclusive, safe, and sustainable.

Digital technology innovation can help mitigate climate change, and as the ITU Secretary-General, Houlin Zhao remarked that society is in the grip of two forces of deep transformations, (i) emerging technologies (AI, Big Data, IoT, 5G) disrupting governments/business and (ii) climate change which disrupts ecosystems [64].

ISO standards help to monitor climate change, measure greenhouse gas emissions and promote good practice in managing the environment. ISO 14080, intends to give organizations a framework to develop consistent, comparable and improved methodologies in the fight against climate change [65], and ISO Guide 84, Guidelines for addressing climate change in standards [66], is aimed at those involved in standards development. 
Also ISO standards committees for IoT, AI, 5G and Smart Cities have an important contribution to measuring, monitoring and generating intelligent efficiencies in human production systems.

\section{SDG 14: Life Below Water}

Seawater drives global systems that makes the Earth habitable. for humankind. Rainwater, drinking water, weather, climate, food, and even the oxygen are all products of the sea.

An innovative ocean-cleaning technology Seabin [67], it collects rubbish floating in bays, estuaries and ports while producing valuable data on pollution levels to inform strategies for cleaning our seas and oceans. Seabin also creates awareness about water pollution and disseminates that message to citizens attempting to energise support to combat ocean pollution.

Peter Kohler of Plastic Tide harnesses emerging technologies in drones [68] to measure and monitor in the battle against plastics. Thousands of aerial photos train an AI algorithm to distinguish between plastic trash and shells, jellyfish or plastic bags. 400 Seabins in 23 countries including Spain, Finland and the USA contributes to gathering vital intelligence on the ocean's plastic pollution.

ICTs are also helping moderate the impact of climate [69] change on human citizens as well as on wildlife. Images taken of the earth from satellites record environmental changes in temperature, sea level or land use while data about the sea floor is captured by sensors on internet cables. Emerging technologies enable us to capture, store and process this information, predict trends, and also recommend changes.

Traceability of fish and management of marine resources are the focus of ISO/TC 234 [70], ISO's technical committee for fisheries and aquaculture, creating opportunities for development of fisheries and aquaculture mindful of sustainable development. ISO/TC 8, Ships and marine technology [71], has 250 sustainability-related standards for building and marine environmental matters related to shipbuilding. Their Subcommittee 2, Marine environment protection, has standards related to the environmental impact of ships and marine technology.

\section{SDG 15: Life on Land}

Technology developers in Skopje's are mapping air pollution [72] using mobile technologies, open source data, sensors and IoT so citizens avoid 
areas with serious air pollution. For World Environment Day [73], the UN is highlighting the need to beat air pollution.

"If you can empower local people to innovate based on local knowledge, that is a really powerful way of driving forward the Sustainable Development Goals,"

- Sam Greene,

International Institute for Environment and Development (IIED).

Internet and social media applications are helping to protect wildlife [74] with apps such as WildScan, used to fight illegal wildlife trading in places such as Thailand and Vietnam. Project Noah allows citizen scientists to share data on wildlife spotting around the world. Kenya has grown its population of endangered black rhinos by $100 \%$ in just 10 years by using drones. Combining smart surveillance, GPS tracking and AI technology with local participation helps save the rhinos from poachers.

Protecting and promoting life on land through better use of resources is the objective of hundreds of ISO standards. ISO 14055 [75] Series, Environmental management - Guidelines for establishing good practices for combatting land degradation and desertification, part of the ISO 14000 family of standards for environmental management and sustainable forestry. ISO 38200, Chain of custody of wood and wood-based products, promotes sustainable sources and traceability in the wood supply chain helping to combat illegal deforestation.

This digital revolution is driven by emerging technologies such as AI, Big Data, IoT, blockchain, 5G [76] and more. These technologies show great promise for accelerating progress towards the United Nations SDGs but progress in digital revolution cannot be allowed to happen at an uneven pace around the world which will lead to a greater digital divide.

One of the main challenges is the growing disparity in both ICT and policy, digital access, and digital literacy. The WSIS Forum has developed as the leading multi-stakeholder ICT for development events in the world, with more than 3,000 participants from over 150 countries leveraging information and communication technologies for SDGs. 
A technology report [77], released by the United Nations High Level Panel [78] on Digital Cooperation that was launched by UN SecretaryGeneral António Guterres. Fabrizio Hochschild acknowledged the Report's recognition of the potential and implications of digital technologies toward the achievement of all 169 targets of the 17 Sustainable Development Goals.

ITU's work on the World Summit on the Information Society Forum, the AI for Global Good Summit, the Broadband Commission for Sustainable Development, ITU's Global Symposium for Regulators, all contribute to SDG17, leaving no one behind, creating an inclusive digital economy and society.

Work to reinforce the capacity of developing countries in standardization is carried out by ISO to ensure standards are globally relevant. Building skills in areas such as strategy, technical and operational expertise and relationships with policy makers, to support their participation in international standardization is a high priority.

The New Rights Pilot Programme, allows countries to participate more actively in ISO standards development in tourism, food products and conformity assessment, helping to improve public welfare in vital areas such as health, safety and environmental protection, creating economic growth and access to international and global markets.

\section{Analysis and Conclusion}

When the UN published the 17 SDGs in 2015, emerging technologies like AI, Big Data, IoT and 5G were just beginning to impact on large scale challenges and opportunities economically, socially and environmentally. As these technologies mature and are applied to more and more sectors and verticals, there is a clear and present need to address sustainability, fairness, safety, security, interoperability, inclusiveness, transparency, efficiency, and usability. Emerging technology standardization and the work of the international SDOs and SSOs is crucial to provide the sustainable society that our citizens deserve. Standards are living documents and evolve as the technologies evolve, which allows stakeholders to strengthen the synergetic relationship between technological innovation and standardization. The use cases examined in this paper under the headings of the 17 United Nations Sustainable Development Goals, provide concrete examples of where emerging technologies have a big part to play in the survival of our planet and 
our economies and our citizens. Standards are what you put in to products, processes and services ... confidence is what people get out.

\section{Acknowledgements}

This paper is supported in part by the ADAPT Centre for Digital Content Technology, which is funded under the SFI Research Centres Programme (Grant 13/RC/2106) and is co-funded under the European Regional Development Fund.

\section{References}

[1] "Transforming Our World: The 2030 Agenda for Sustainable Development", UN General Assembly Resolution A/RES/70/1 Resolution adopted by the General Assembly, Sept. 2015, [online] Available: http: //www.un.org/en/development/desa/population/migration/generalass embly/docs/globalcompact/A_RES_70_1_E.pdf, visited 21th January 2020.

[2] J. Wu et al., "Information and Communications Technologies for Sustainable Development Goals: State-of-the-Art Needs and Perspectives", IEEE Commun. Surveys \& Tutorials, 2018.

[3] New partnership between ITU and FAO to bolster ICT innovation in agriculture https://www.itu.int/en/mediacentre/Pages/2017-CM17.aspx, visited 20th January 2020.

[4] United Nations Department of Economic and Social Affairs, "World population projected to reach 9.7 billion by 2050", July 2015, http: //www.un.org/en/development/desa/news/population/2015-report.html, visited 19th January 2020.

[5] WaPOR, remote sensing for water productivity http://www.fao.org/in-a ction/remote-sensing-for-water-productivity/en/, visited 19th January 2020.

[6] WaPOR, remote sensing for water productivity http://www.fao.org/in-a ction/remote-sensing-for-water-productivity/en/, visited 19th January 2020.

[7] How AI can improve agriculture for better food security, https://news.i tu.int/ai-for-food-security/

[8] Robotic Farm Completes 1st Fully Autonomous Harvest, https://www.li vescience.com/60567-robotically-tended-farm-completes-first-harvest .html, visited 20th January 2020. 
[9] Innovation with a Purpose: The role of technology innovation in accelerating food systems transformation https://www.weforum.org/reports/ innovation-with-a-purpose-the-role-of-technology-innovation-in-accel erating-food-systems-transformation, visited 2nd January 2020.

[10] How new technologies can transform healthcare and make us healthier, https://news.itu.int/how-new-technologies-can-transform-healthcare-a nd-make-us-healthier/, visited 20th January 2020.

[11] Digital Health for Africa, https://www.itu.int/en/mediacentre/Pages/201 7-CM21.aspx, visited 20th January 2020.

[12] Be Healthy, BE Mobile, https://www.itu.int/en/ITU-D/ICT-Application s/eHEALTH/Be_healthy/Pages/Be_Healthy.aspx, visited 20th January 2020.

[13] How new technologies can transform healthcare and make us healthier, https://news.itu.int/how-new-technologies-can-transform-healthcare-a nd-make-us-healthier/, visited 20th January 2020.

[14] ITU-Academia Partnership Meeting highlights changing needs for digital skills, https://news.itu.int/itu-academia-partnership-meeting-highli ghts-changing-needs-for-digital-skills/, visited 20th January 2020.

[15] ILO-ITU Digital Skills for Jobs Campaign to equip 5 million youth with job-ready digital skills, https://www.itu.int/en/ITU-D/Digital-Inclusion /Youth-and-Children/Pages/Digital-Skills.aspx, visited 20th January 2020.

[16] Let's work together to build a safer internet for children https://news.itu .int/lets-work-together-to-build-a-safer-internet-for-children/, visited 20th January 2020.

[17] How can AI improve education?, https://news.itu.int/call-for-proposal s-future-artificial-intelligence-education/, visited 20th January 2020.

[18] An innovative solution to make online services available to all, https: //news.itu.int/online-services-half-world-unconnected/, visited 20th January 2020.

[19] Why disarmament sits at the intersection between technology and security, https://news.itu.int/disarmament-intersection-technology-security/, visited 20th January 2020.

[20] Making sure AI is harnessed for good, https://news.itu.int/making-sure -ai-is-harnessed-for-good/, visited 20th January 2020.

[21] The future is better than you think:' Predictions on AI and development from Ray Kurzweil, https://news.itu.int/the-future-is-better-than-you-t hink-predictions-on-ai-and-development-from-ray-kurzweil/, visited 14th January 2020. 
[22] ITU-T Focus Group Digital Financial Services: Distributed Ledger Technologies and Financial Inclusion, https://www.itu.int/en/ITUT/ focusgroups/dfs/Documents/201703/ITU_FGDFS_Report-on-DLT-a nd-Financial-Inclusion.pdf, visited 20th January 2020.

[23] WEF Global Gender Gap Report, http://www3.weforum.org/docs/WE F_GGGR_2018.pdf, visited 20th January 2020.

[24] Gender bias is a threat to future Artificial Intelligence (AI) applications: Opinion, https://news.itu.int/gender-bias-is-a-threat-to-future-artificia 1-intelligence-ai-applications-opinion/

[25] African Girls Can Code Initiative (AGCCI) 2018-2022 https://www.itu. int/en/ITU-D/Regional-Presence/Africa/Pages/African-Girls-Can-Co de.aspx, visited 21th January 2020.

[26] WEF The Future of Jobs Report 2018 http://www3.weforum.org/docs/ WEF_Future_of_Jobs_2018.pdf, visited 21th January 2020.

[27] Empowering girls to code for a bright and promising future, https://news .itu.int/empowering-girls-to-code-for-a-bright-and-promising-future/, visited 21th January 2020.

[28] How can we close the digital gender gap? 4 key questions answered, https://news.itu.int/close-digital-gender-gap-4-questions/, visited 21th January 2020.

[29] ISO 26000 Social Responsibility https://www.iso.org/iso-26000-social -responsibility.html, visited 21th January 2020.

[30] How big data is boosting productivity for smallholder farmers, https: //news.itu.int/how-big-data-is-boosting-productivity-for-smallholder-f armers/, visited 20th January 2020.

[31] How big data is boosting productivity for smallholder farmers, https: //news.itu.int/how-big-data-is-boosting-productivity-for-smallholder-f armers/, visited 20th January 2020.

[32] E-Agriculture in Action: Big Data for Agriculture, http://www.fao.org/ 3/ca5427en/ca5427en.pdf

[33] Pan Pacific ties up with Singapore startup for digital transformation, ht tp://www.ttgasia.com/2018/10/08/pan-pacific-ties-up-with-singaporestartup-for-digital-transformation/, visited 20th January 2020.

[34] The Technical Barriers to Trade (TBT) Agreement, https://www.wto.or g/English/Tratop_E/tbt_e/tbt_e.htm, visited 20th January 2020.

[35] ISO 45001 Occupational health and safety, https://www.iso.org/iso-45 001-occupational-health-and-safety.html, visited 20th January 2020.

[36] ISO 37001 Anti-bribery management systems, https://www.iso.org/iso37001-anti-bribery-management.html 
[37] How Myanmar's policies accelerated digital development, https://news .itu.int/how-myanmars-policies-accelerated-digital-development/, visited 20th January 2020.

[38] Why we need responsible innovation: WIPO's Francis Gurry, https://ne ws.itu.int/why-we-need-responsible-innovation-wipos-francis-gurryvideo/, visited 20th January 2020.

[39] World Summit on the Information Society Forum, Cooperation in Action to Improve People's Lives: The Broadband Commission for Sustainable Development, https://www.itu.int/net4/wsis/forum/2019 /Agenda/ViewSession/243, visited 20th January 2020.

[40] Collaborative business relationship management systems - Requirements and framework, https://www.iso.org/standard/72798.html, visited 20th January 2020.

[41] ISO/TC 279 Innovation management https://www.iso.org/committee/45 87737.html, visited 20th January 2020.

[42] World Telecommunication and Information Society Day to focus on inclusive standards, https://news.itu.int/world-telecommunication-a nd-information-society-day-to-focus-on-inclusive-standards/, visited 20th January 2020.

[43] Bridging the Standardization Gap (BSG), https://www.itu.int/en/ITU-T /gap/Pages/default.aspx, visited 20th January 2020.

[44] United Nations Economic Commission for Europe (UNECE) https://ww w.unece.org/info/ece-homepage.html, visited 20th January 2020.

[45] UN International Day of Persons with Disabilities, https://www.un.org /en/observances/day-of-persons-with-disabilities, visited 20th January 2020.

[46] ISO 26000 Social responsibility, https://www.iso.org/iso-26000-social -responsibility.html, visited 20th January 2020.

[47] World Economic Forum's 2018 Global Risks Report, https://www.we forum.org/reports/the-global-risks-report-2018, visited 20th January 2020.

[48] World Economic Forum's Water Security Rewired platform, http://ww w3.weforum.org/docs/Environment_Team/00042829_Water_initiative. pdf, visited 20th January 2020.

[49] World Bank: Water, http://www.worldbank.org/en/topic/water, visited 20th January 2020.

[50] World Bank: Water, http://www.worldbank.org/en/topic/water, visited 20th January 2020. 
[51] ISO 30500:2018. Non-sewered sanitation systems, https://www.iso.org/ standard/72523.html, visited 20th January 2020.

[52] The United Nations University (UNU) Sustainable Development Goal 7, https://unu.edu/explore/sustainable-development-goal-7, visited 20th January 2020.

[53] ITU Resource efficiency towards circular economy strategy, https://ww w.itu.int/md/D18-SG02-C-0281, visited 20th January 2020.

[54] ITU Y.4903/L.1603 "Key Performance Indicators for Smart Sustainable Cities to assess the achievement of Sustainable Development Goals", https://www.itu.int/itu-t/recommendations/rec.aspx?rec=12884, visited 20th January 2020.

[55] Closing the Loop, http://closingtheloop.eu/, visited 20th January 2020.

[56] Why Seoul is one of the world's 'smartest' cities when it comes to energy, https://news.itu.int/energywise-seoul-worlds-smartest-city/, visited 20th January 2020.

[57] ISO 20400:2017 - Sustainable procurement, https://www.iso.org/standa $\mathrm{rd} / 63026 . \mathrm{html}$, visited 20th January 2020.

[58] ISO 15392:2019 - Sustainability in buildings and civil engineering works - General principles, https://www.iso.org/standard/69947.html, visited 20th January 2020.

[59] ISO 20245:2017 - Cross-border trade of second-hand goods, https://ww w.iso.org/standard/68820.html, visited 20th January 2020.

[60] One UN for Climate: Let's unite to build Smart Sustainable Cities, https: //news.itu.int/one-un-for-climate-lets-unite-to-build-smart-sustainabl e-cities/, visited 20th January 2020.

[61] How we can turn digital technology innovation into climate action, https: //news.itu.int/how-we-can-turn-digital-technology-innovation-into-cl imate-action/, visited 20th January 2020.

[62] Focus Group on Environmental Efficiency for Artificial Intelligence and other Emerging Technologies (FG-AI4EE), https://www.itu.int/en/ITU -T/focusgroups/ai4ee/Pages/default.aspx, visited 20th January 2020.

[63] United 4 Smart Sustainable Cities, https://www.itu.int/en/ITU-T/ssc/u nited/Pages/default.aspx, visited 20th January 2020.

[64] How we can turn digital technology innovation into climate action, https: //news.itu.int/how-we-can-turn-digital-technology-innovation-into-cl imate-action/, visited 20th January 2020.

[65] ISO 14080:2018. Greenhouse gas management and related activities, ht tps://www.iso.org/standard/67452.html, visited 20th January 2020. 
[66] ISO Guide 84, Guidelines for addressing climate change in standards, https://www.iso.org/standard/72496.html, visited 20th January 2020.

[67] How Seabin is helping clean the oceans of plastic waste, https://news.itu .int/how-seabin-is-helping-clean-the-oceans-of-plastic-waste/, visited 20th January 2020.

[68] How AI-powered drones are helping fight ocean plastic, https://news.itu .int/ai-drones-ocean-plastic/, visited 20th January 2020.

[69] Enlisting technologies in the fight against climate change, https://news.i tu.int/technologies-fight-against-climate-change/, visited 20th January 2020.

[70] ISO/TC 234 - Fisheries and aquaculture, https://www.iso.org/committe e/541071.html, visited 20th January 2020.

[71] ISO/TC 8 - Ships and marine technology, https://www.iso.org/committe e/45776.html, visited 20th January 2020.

[72] How Skopje, North Macedonia is using innovative tech to clean up air pollution, https://news.itu.int/how-skopje-north-macedonia-is-using-i nnovative-tech-to-clean-up-air-pollution/, visited 20th January 2020.

[73] UN: Air Pollution, https://www.worldenvironmentday.global/about/air -pollution, visited 20th January 2020.

[74] World Wildlife Day: 5 ways ICTs are helping to protect wildlife, https: //news.itu.int/world-wildlife-day-5-ways-icts-are-helping-to-protect-w ildlife/, visited 20th January 2020.

[75] ISO 14055-1:2017 - Environmental management, https://www.iso.org/ standard/64646.html, visited 20th January 2020.

[76] Let's align to make the digital revolution a development revolution https: //news.itu.int/lets-align-to-make-the-digital-revolution-a-development -revolution/, visited 20th January 2020.

[77] "The Age of Digital Interdependence", Report of the High-level Panel on Digital Cooperation, https://digitalcooperation.org/report, visited 20th January 2020.

[78] UN News, UN chief urges top digital tech panel to come up with 'bold, innovative ideas' for an 'inclusive' future, https://news.un.org/en/story /2019/01/1031092, visited 20th January 2020. 


\section{Biographies}

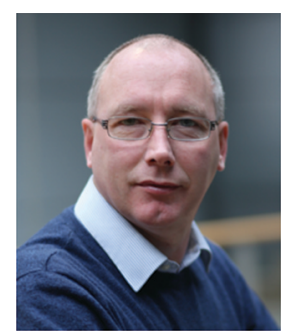

Ray Walshe 10 Years working in Industry and 25 Years in Academia in Dublin City University, Ray graduated with honours in Electronic Engineering from University of Limerick in 1991 and worked with LM Ericsson, Software and Systems Engineering Limited and Siemens as Software Consultant. Joining School of Computing DCU in 1995 he is a Funded Researcher at Science Foundation Ireland Insight Centre for Data Analytics and at Science Foundation Ireland Adapt Centre for Digital Content, where his research activities include Cloud Computing, Big Data, IoT and AI Standardization. Ray is senior member of IEEE and member of IEEE European Public Policy Committee on ICT. He is a Digital Leader and Standards Consultant with the World Economic Forum (2018-Present) and his international standards work includes ISO/IEC JTC1 SC42 Artificial Intelligence Standards Editor, Steering Committee Member for European Commission Joint Initiative on Standardisation, Chair of StandICT.eu Expert Advisory Group and Coordinator of Horizon 2020 ELITE-S Standardization Fellowships. In 2019 Ray was appointed Member of United Nations Economic Commission for Europe (UNECE) Regulatory Cooperation and Standardization Policies and in 2020 was appointed to the CEN-CENELEC Focus Group on AI. 


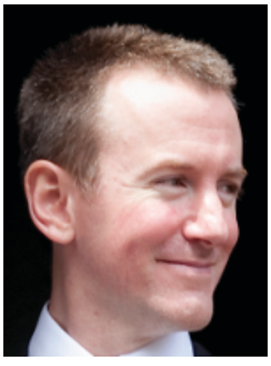

Kevin Casey is a lecturer at Maynooth University (MU). Before his current position he served as a lecturer at Dublin City University. Having completed a BSc and MSc in Computer Science at University College, Dublin, he began lecturing at GCD in 1994. He left in 2002 to take up a position as researcher in the School of Computer Science and Statistics at Trinity College Dublin. His current research is focused on educational data analytics and he is involved with several initiatives in relation to Computational Thinking, largely though his work with the PACT group at MU (http://pact.cs.nuim.ie/). Kevin holds a $\mathrm{PhD}$ in Computer Science from Trinity College, Dublin.

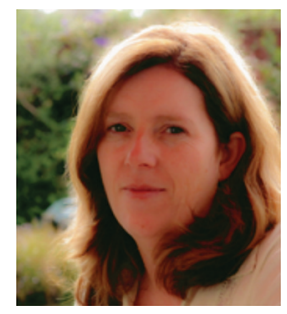

Jane Kernan Ms Kernan has over 20 year's experience as Lecturer in the School of Computing in Dublin City University, Ireland, She is co-ordinator for 1st and 2nd Years Progamme in Computing, former Chair of MSc. In IT and Chair of the Graduate Diploma in IT. Jane delivers graduate and postgraduate course in Business Database Management and Business Applications and has extensive experience supervising student projects. Jane conducts research in the CloudCORE Research Group and the European Industry University Research Association (EIURA). She was Local Chair for EIURA Cloud Forum, 23rd Irish Conference on Artificial Intelligence \& Cognitive Science and the European Commission's Startup Europe initiative including Startup Europe Week, Startup Europe University Network and the 
SEC2U initiative. More recently Jane has been conducting research on Impact of Technology Standardization and has published book chapters on the Big Data Standardization.

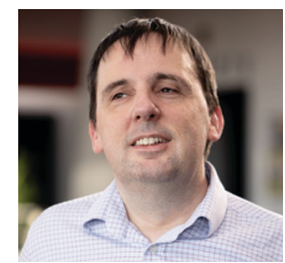

Donal Fitzpatrick is a lecturer in the School of Computing. His research interests are in the area of interface design, with particular emphasis on the creation of multimodal interfaces. Dr. Fitzpatrick's work has primarily focussed on the accessibility of all user interfaces for people with disabilities. he is currently working on the Euromath project which aims to improve the educational opportunities for blind people, by creating tools to provide access to mathematics in a non-visual way. From 2014-17, Dr. Fitzpatrick was coordinator of the FP7 EAGLE project. Dr. Fitzpatrick has previously been principle Investigator in the SFI-funded project entitled Barrier-Free Access to Mathematics. In 2014 Dr. Fitzpatrick was the recipient of the Enable award which recognised his outstanding contribution to the field of research into Assistive Technology for persons with Disabilities. 